\title{
The Influences of Emotional Labor on Job Involvement: The Effects of Mediating Role With PE Fit
}

\author{
Ping-Fu Hsu ${ }^{1}$ \\ ${ }^{1}$ International College, Krirk University, Thailand \\ Correspondence: Ping-Fu Hsu, Assistant Professor, International College, Krirk University, No. 3 Soi Ramindra \\ 1, Khwaeng Anusawari, Khet Bang Khen, Krung Thep Maha Nakhon 10220, Thailand. E-mail: \\ joey5621@gmail.com
}

Received: April 2, 2021

Accepted: April 23, 2021

Online Published: May 6, 2021

doi:10.20849/ajsss.v6i2.885

URL: https://doi.org/10.20849/ajsss.v6i2.885

\begin{abstract}
Research on emotional labor focus on related employees' work outcomes, well-beings, and dissonances that could be ignored some moderation effects especially between emotional labor and job involvement. This study focused on difference types of PE fit that individual fit take a mediation role between emotional labor and job involvement. Data from 230 convenience store full time $(71.7 \%)$ and part time job (28.3\%) working employees were collected. Results indicate that difference types of PE fit predicated mediating effects influenced the relationship between predictor (emotional labor) and criterion variables (job involvement). Further, person organization fit evidenced positive effects on job identity.
\end{abstract}

Keywords: emotional labor, PE fit, job involvement, job identity, job participation

\section{Introduction}

Many studies in recent years have focus on the emotional labor process (Grandey, 2000; Hsu, 2019; Zhang, Yu \& Jiang, 2020), which includes the perception of emotional display rules (i.e., emotional demands from the workplace), the perception of intra-psychic experiences (i.e., emotion regulation tend to be self-reported; Hsu, 2019; Grandey, Dieffendorff, \& Rupp, 2013).

Few studies conducted to job involvement which Wu \& Cheng (2006) noted the interaction relationship between job involvement and emotional labor. Few evidences to examine the direct and indirect mediation effects between emotional labor and job involvement (e.g. Hsu, 2015).

The studies of person-environment fit have been ignited from post 1980's, several researchers investigated person-job fit and person-organization fit as their main variables (Kristof-Brown, Zimmerman, \& Johnson, 2005). Kristof-Brown \& Billsberry (2013) have divided the P-E fit literatures into two categories, one is the employees' perspective emphasized direct perceived fit (Cable \& DeRue, 2002), and the other is examined the difference between person and environment, that emphasized indirect fit (also reciprocal fit; Chuang, Shen, \& Judge, 2015).

There is no empirical study in Taiwan concern in the moderating roles of perceived person - environment fit between emotional labor and job involvement (Hsu, 2019). Up to this point, however, there were few empirical studies of the effects of positive emotional labor on job involvement of chain convenience store's employees. Thus, this paper will focus on a conceptual framework of person-environment fit for examining the influences and relationships between emotional labor and job involvement.

\section{Theoretical Review and Research Hypotheses}

\subsection{Emotional Labor and Job Involvement}

According to Kanungo's (1982) point of view that the main concepts of job involvement includes job identity and job participation.

Job involvement are influenced by individual characteristics, job features (i.e., emotional labor high or low), supervisor variable, and character recognition (Brown, 1996). Accordingly, we proposed that employees toward the positive emotion even they load high emotional labor, they would improve their job involvement.

Regarding positive emotional labor that attribute employees' psychological capital, Avey, Luthans, \& Youssef (2010) describes as psychological capital is an important individual resource that improve individual 
development, job performance (Darvishmotevali \& Ali, 2020) and job involvement in workplace. More important except positive emotional labor show positive correlation between emotional labor and job involvement (Yoo \& Arnold; Siu et al., 2014), further we have to think over any moderator influence among them.

Hypothesis 1: Emotional labor has a direct and positive or negative influenced on job involvement.

\subsection{Perceived Person-Environment Fit: The Mediator Between Emotional Labor and Job Involvement}

Fit or mis-fit perspective between person (P) variables (i.e., capability, demand, and value etc.) and environment (E) variables (i.e., job demand, job attribution, social environment, and organizational culture etc.) which lead to positive or negative results (Schneider, 2001).

Recently, P-E Fit theory has been classified two research categories, the one is emphasized perceived direct fit from employees' view and the other is indirect fit, namely, measure fit from person and environment individually (Kristof-Brown \& Billsberry, 2013). Base on the perspective of complementary fit, perceived fit, emotional regulation mechanism, and self-regulation theory, we propose P-E fit would mediate the relationship between emotional labor and job involvement.

With the expectation of measuring double dimensions such as person-group, and person-supervisor fit (e.g., reciprocal fit; Chuang et al., 2015) researchers always use each dimension to investigate fit degree (Herdman \& Carlson, 2009). Now we head to multiple dimensions P-E fit concepts. Regarding perceived fit (PO, PJ fit) and reciprocal fit (PS, PG fit) we propose the following hypothesis:

Hypothesis 2: Emotional labor has a direct and positive influenced on PE fit.

Hypothesis 3: PE fit has a direct and positive influenced on job involvement.

Hypothesis 4: Person-environment fit (PJ, PO, PS, PG fit) reveal mediating effects on the relationship between emotional labor and job involvement.

\subsection{Research Framework}

According to this study of purpose and discussed literatures, we provide this research framework, as following:

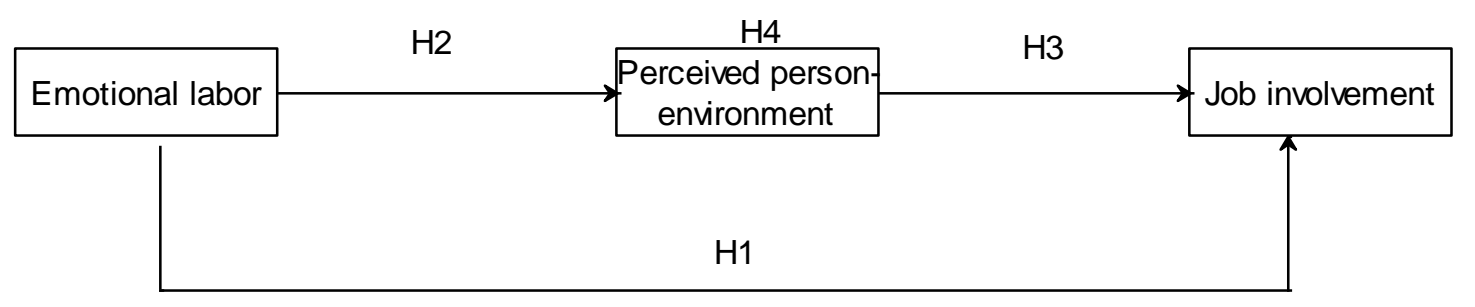

Figure 1. Research framework

\section{Research Method and Analyses}

Data from 230 (male $=78$; female $=152$ ) convenience store employees in Taiwan were used in present study. Employees rates the three constructs of emotional labor scare (Lin, 2000), two constructs of job involvement (Kanungo, 1982) and four constructs of PE fit (Cable \& DeRue, 2002; Lauver \& Kristof-Brown, 2001).

The following domain scales containing 51 items were distinguished, (alphas, CR, and AVE among parentheses): (1) Basic emotional display $(.864 ; .796 ; .362)$ : describes employee's emotional labor getting high and show that the emotional burden getting high. (2) Surface emotion control $(.865 ; .667 ; .406)$ : shows worker's surface emotional control is high, it represents their emotional burden is high. (3) Deep acting $(.874 ; .811 ; .383)$ : pointed when the workers execute emotional mission, they need more efforts to control their true feelings. (4) Job identity $(.862 ; .611 ; .301)$ : illustrates employees' cognition with their job. (5) Job participation $(.867 ; .643 ; .390)$ : describes employees engaged the degree of job. (6) PJ fit $(.862 ; .790 ; .359)$ : covers the congruence between employees and jobs. (7) PO fit $(.866 ; .866 ; .522)$ : describes the fit between employees and organization. (8) PS fit $(.859 ; .867 ; .491)$ : illustrates the congruence between employees and supervisors. (9) PG fit $(.864 ; .820 ; .437)$ : covers the congruence between employees and group. All scale items were measured on 5-point Likert scale. Tinsley and Tinsley (1987) suggested an item-subject ration of between 3 to 10 or 5 to 10 from the biggest conceptual items $(\mathrm{PE}$ fit $=26)$ therefore 300 subjects were collected, whereas Comrey $(1988)$ has stated that a 
sample size of 200 subjects is sufficient for a factor analysis containing up to 40 or fewer variable.

A confirmatory factor analysis (maximum likelihood estimation; Amos 21.0) including all items scales confirms the measurement models (see Table 1). We applied several methods ex ante (before) and ex post (after) to avoid common method variance (Podsakoff, Mackenzie, Lee, \& Podsakoff, 2003). Ex ante we used both separation approach of data collecting and design approach of instrument developing. As ex post means of control, the single-factor test was run. An exploratory factor analysis including all indicators reveals that many factors explain $66.247 \%$ of the variance. By contrast, one general factor explains $27.016 \%$ of the variance only. Hence, this study doesn't exist common method variance.

Regression analysis was applied to measure the relationship between predictors and outcome variables. Then, we used the mediator approach proposed by Preacher and Hayes (2008) and Hayes (2012), including a bootstrapping procedure for testing the indirect effects.

\section{Result}

\subsection{Measurement Model Analyses}

All variables models of fit goodness index are reported in Table 1. We followed Hu and Bentler (1998) suggested the goodness index standard values, except PPJ fit of NNFI $=.858$, RMSEA $=.107$, and SRMR $=.0587$ are out of little range, others represented well goodness. Bivariate correlations are presented in Table 2. All variables are provided significance.

In general, as observed in Figure 2, the mediator of low PPE offers horizontal line means that high and low emotional labor would not influence on job involvement.

In contrast, high PPE group would be affected the relationship between emotional labor and job involvement.

Table 1. Fit index of variables model

\begin{tabular}{lccccccccc}
\hline Variable & $X^{2}$ & $X^{2} / d f$ & NFI & NNFI & CFI & GFI & AGFI & RMSE & SRMR \\
& & & & & & & & A & \\
\hline BE & 51.761 & 3.697 & 0.874 & 0.855 & 0.903 & 0.939 & 0.878 & 0.109 & 0.0588 \\
SA & 0 & 0 & 1 & - & 1 & 1 & - & 0.377 & 0 \\
DA & 20.47 & 1.462 & 0.951 & 0.975 & 0.984 & 0.975 & 0.950 & 0.045 & 0.0345 \\
\hline JI & 62.586 & 12.517 & 0.716 & 0.453 & 0.726 & 0.908 & 0.724 & 0.224 & 0.1089 \\
JP & 29.565 & 5.913 & 0.894 & 0.816 & 0.908 & 0.952 & 0.855 & 0.146 & 0.0668 \\
\hline PPJ & 50.512 & 3.608 & 0.876 & 0.858 & 0.906 & 0.939 & 0.878 & 0.107 & 0.0587 \\
PPO & 35.146 & 3.905 & 0.941 & 0.925 & 0.955 & 0.951 & 0.885 & 0.113 & 0.0402 \\
PPS & 30.667 & 2.191 & 0.955 & 0.962 & 0.975 & 0.963 & 0.925 & 0.072 & 0.0336 \\
PPG & 37.081 & 4.120 & 0.916 & 0.890 & 0.934 & 0.948 & 0.878 & 0.117 & 0.0455 \\
\hline value & $>.1$ & $<5$ & $>.9$ & $>.9$ & $>.9$ & $>.9$ & $>.8$ & $<0.1$ & $<.05$ \\
\hline
\end{tabular}

\subsection{Hypothesis Testing}

Hypothesis 1 (see Table 3) tests the relationship between emotional labor and job involvement that represented $\mathrm{BE}$ to job identity (Beta $=.344 ; \mathrm{p}<.000)$, DA to job participation (Beta $=.223 ; \mathrm{p}<.05$ ), and both general models showed significance. The variance inflation factor (VIF) are lower than 5 that means the tolerance value under .2 (Belsley, 1991). Hypothesis 2 tests the relationship between emotional labor and person-environment fit that described EL to PE (Beta $=.684 ; \mathrm{p}<.000)$. Hypothesis 3 tests the relationship between person-environment fit and job involvement that represented PE to JINVO $($ Beta $=.637 ; \mathrm{p}<.000)$. 
Table 2. Pearson correlations, mean and SD of the all variables $(\mathrm{N}=230)$

\begin{tabular}{|c|c|c|c|c|c|c|c|c|c|c|c|c|c|c|}
\hline Variable & Mean & S.D. & EL & JINVO & PE & $\mathrm{BE}$ & SA & DA & JI & JP & PPJ & PPO & PPS & PPG \\
\hline EL & 4.005 & .450 & 1 & & & & & & & & & & & \\
\hline JINVO & 3.333 & .540 & $.428 * *$ & 1 & & & & & & & & & & \\
\hline PE & 3.768 & .498 & $.684 * *$ & $.637 * *$ & 1 & & & & & & & & & \\
\hline $\mathrm{BE}$ & 4.080 & .482 & $.831 * *$ & $.414 * *$ & $.587 * *$ & 1 & & & & & & & & \\
\hline SA & 4.017 & .584 & $.878 * *$ & $.333 * *$ & $.528^{*}$ & $.635^{* *}$ & 1 & & & & & & & \\
\hline DA & 3.918 & .536 & $.815^{* *}$ & $.343 * *$ & $.621 * *$ & $.503 * *$ & $.552 * *$ & 1 & & & & & & \\
\hline JI & 3.548 & .558 & $.447 * *$ & $.774 * *$ & $.592 * *$ & $.439 * *$ & $.333^{* *} *$ & $.367^{* *}$ & 1 & & & & & \\
\hline JP & 3.331 & .731 & $.322^{* * *}$ & $.800 * *$ & $.523 * *$ & $.258 * *$ & $.283^{* *}$ & $.270 * *$ & $.753 * *$ & 1 & & & & \\
\hline PPJ & 3.696 & .575 & $.536^{* *}$ & $.688 * *$ & $.812 * *$ & $.502 * *$ & $.459 * *$ & $.466^{*}$ & $.637 * *$ & $.568 * *$ & 1 & & & \\
\hline PPO & 3.623 & .662 & $.481^{* *}$ & $.485^{* *}$ & $.825 * *$ & $.441 * *$ & $.333^{* *}$ & $.452^{* *}$ & $.448 * *$ & $.381 * *$ & $.553^{* *}$ & 1 & & \\
\hline PPS & 3.834 & .615 & $.635^{* *}$ & $.471 * *$ & $.852 * *$ & $.540 * *$ & $.498 * *$ & $.571^{* *}$ & $.425^{* *}$ & $.396 * *$ & $.551^{* *}$ & $.608 * *$ & 1 & \\
\hline PPG & 3.919 & .546 & $.606^{* *}$ & $.481 * *$ & $.834 * *$ & $.469 * *$ & $.477 * *$ & $.583 * *$ & $.466^{* * *}$ & $.403 * *$ & $.618 * *$ & $.529 * *$ & $.666^{* * *}$ & 1 \\
\hline
\end{tabular}

Note: $* \mathrm{p}<.05 ; * * \mathrm{p}<.01$

Table 3. Summary of Linear Regression for EL predicting job involvement

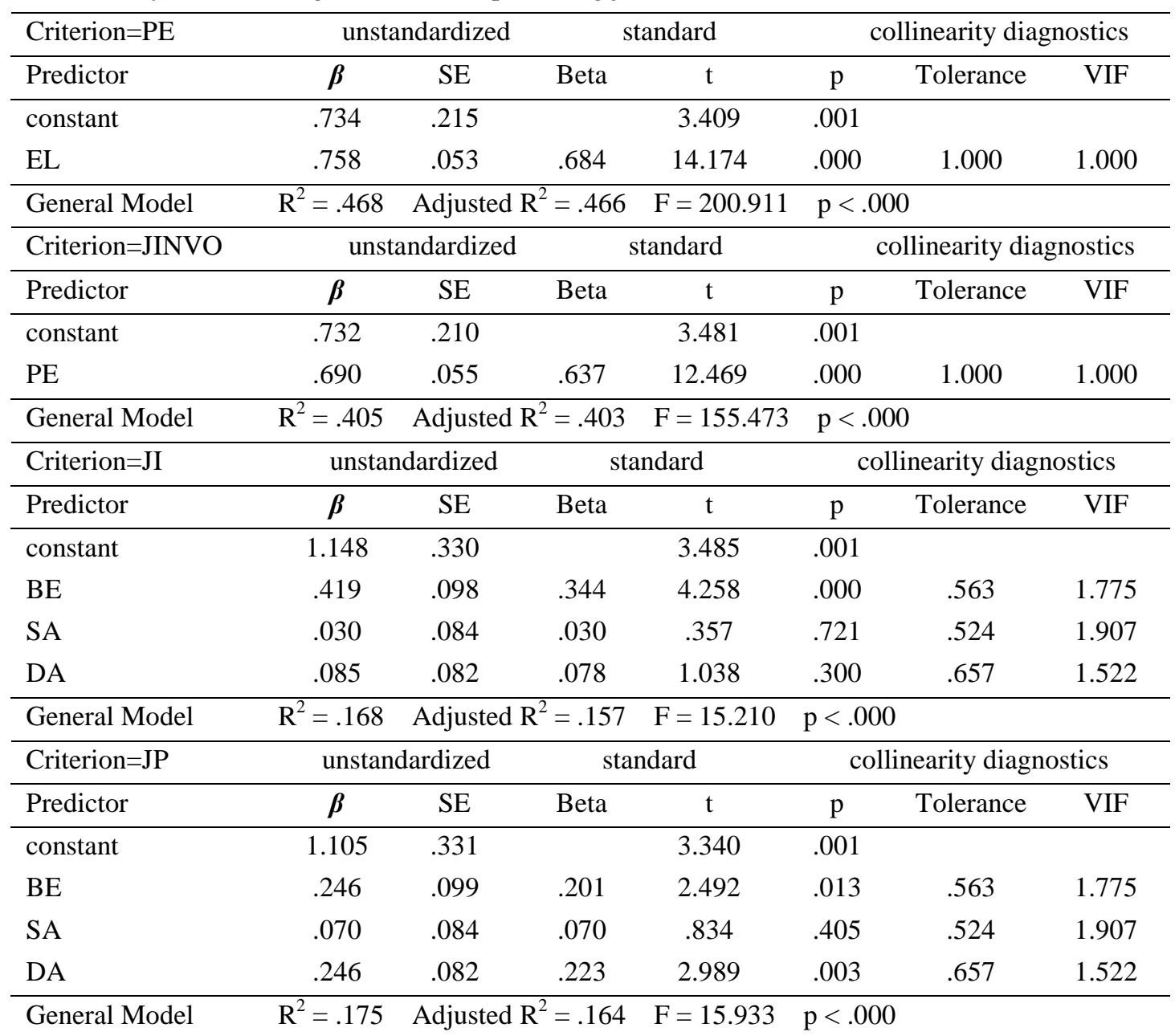

Note $\mathrm{PE}=$ person-environment fit; $\mathrm{EL}=$ emotional labor; JINVO = job involvement;

$\mathrm{BE}=$ basic emotion display; $\mathrm{SA}=$ surface emotion control; $\mathrm{DA}=$ deep acting . 
Mediating effects of person-environment fit on the relationship between emotional labor and job involvement are shown in Table 4 and Figure 2. The indirect level of the influence of emotional labor on job involvement through person-environment was 1.054. In addition, direct levels of the influence of emotional labor on job involvement reached the significance level. Person-environment fit revealed partially mediating effects on the relationship between emotional labor and job involvement. The results showed that emotional labor can indirectly influence job involvement through mediating processes of person-environment fit.

Mediating effects of person-environment fit on the relationship between emotional labor and job involvement are shown in Table 4 and Figure 2. The results demonstrated a significant relationship between independent variables and mediators; there were significant relationships between mediators and dependent variables. Direct levels of the influence of person-environment fit on job involvement reached significant levels, indicating the partially mediating effects of emotional labor and job involvement. In other words, the influence of person-environment fit on job involvement involves both direct and indirect levels. The indirect level (.531) was more significant than the direct level (-.017). According to the results, emotional labor can indirectly influence job involvement by the mediating processes of perceived person-environment. Thus, Hypothesis 4,"perceived person-environment reveal mediating effects on the relationship between emotional labor and job involvement," was supported by this study.

Table 4. Direct \& indirect effects \& $95 \%$ confidence intervals for meditational model

\begin{tabular}{|c|c|c|c|c|c|}
\hline \multirow[t]{2}{*}{ Model pathways } & \multirow[t]{2}{*}{ Effect } & \multirow[t]{2}{*}{ SE } & \multirow[t]{2}{*}{$\mathrm{t}$ value } & \multicolumn{2}{|c|}{$95 \% \mathrm{CI}$} \\
\hline & & & & LLCI & ULCI \\
\hline \multicolumn{6}{|l|}{ Total Effects } \\
\hline $\mathrm{EL} \rightarrow \mathrm{PE}$ fit $\rightarrow$ JI & $.514 *$ & .072 & 7.155 & .372 & .655 \\
\hline \multicolumn{6}{|l|}{ Direct Effects } \\
\hline $\mathrm{EL} \rightarrow \mathrm{PE}$ fit $\rightarrow$ JI & -.017 & .084 & -.204 & -.183 & 149 \\
\hline Indirect Effects & \multicolumn{5}{|c|}{ Boot SE } \\
\hline $\mathrm{EL} \rightarrow \mathrm{PE}$ fit $\rightarrow$ JI & $.531 *$ & \multicolumn{2}{|c|}{.069} & 416 & 683 \\
\hline \multicolumn{6}{|l|}{ Partially indirect effect } \\
\hline $\mathrm{EL} \rightarrow \mathrm{PE}$ fit $\rightarrow \mathrm{JI}$ & $.982 *$ & \multirow{2}{*}{\multicolumn{2}{|c|}{.106}} & .782 & 1.205 \\
\hline \multicolumn{4}{|c|}{ Completely indirect effect } & & \\
\hline $\mathrm{EL} \rightarrow \mathrm{PE}$ fit $\rightarrow \mathrm{JI}$ & $.442 *$ & \multicolumn{2}{|c|}{.051} & 350 & .549 \\
\hline \multicolumn{6}{|c|}{ Ratio of indirect to direct } \\
\hline $\mathrm{EL} \rightarrow \mathrm{PE}$ fit $\rightarrow \mathrm{JI}$ & -30.972 & \multirow{2}{*}{\multicolumn{2}{|c|}{.225}} & .699 & 1.579 \\
\hline \multicolumn{4}{|c|}{ R-squared mediation effect } & & \\
\hline $\mathrm{EL} \rightarrow \mathrm{PE}$ fit $\rightarrow \mathrm{JI}$ & .183 & \multicolumn{2}{|c|}{.060} & .063 & 296 \\
\hline
\end{tabular}

Note: * Empirical $95 \%$ confidence interval does not overlap with zero

$\mathrm{PE}$ fit = person-environment fit; $\mathrm{EL}=$ emotional labor; $\mathrm{JI}=$ job involvement

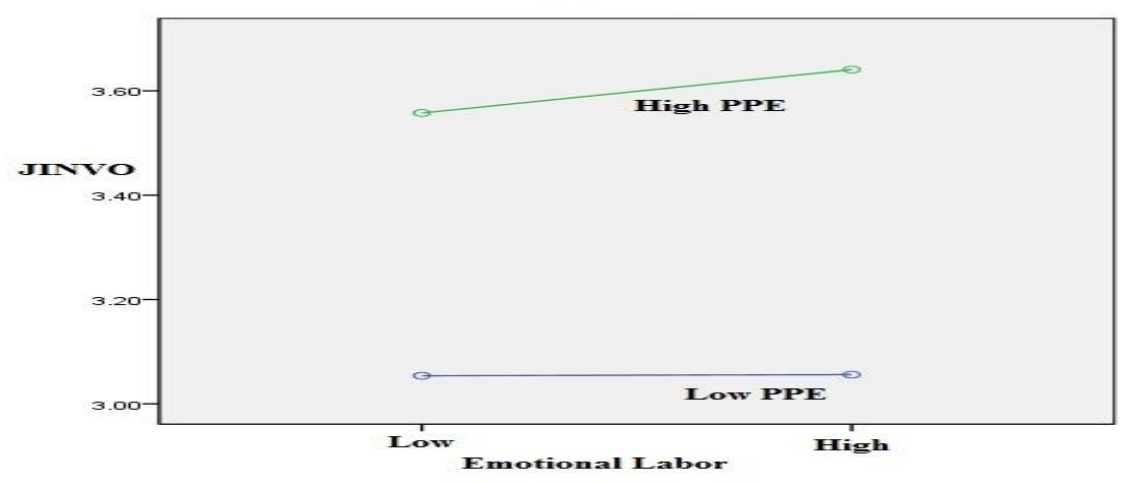

Figure 2. Mediating effects of PE fit 


\section{Discussion and Conclusions}

This paper describing PE fit mediating the relationships between emotional labor and job involvement, we have made the points that (a) emotional labor can indirectly influence job involvement by the mediating processes of perceived person-environment, (b) person-environment fit revealed partially mediating effects on the relationship between emotional labor and job involvement, (c) among emotional labor, PE fit, and job involvement regarding significance positive effects, (d) positive emotional procession within suitable fit concept decreases emotional labor burden than increases job involvement. The finding shows that high level perceived fit with perceived emotional demand-fit in front-line service workers can reflate employees' feelings of fitting in efficently. This result supported the findings of Fox, Webster, \& Casper (2018), Hsu (2019; 2015), Lin \& Hsu (2021) and Yoo \& Arnold (2014).

All evidences revealed that Diefendorff (2014) noted perceived emotional demand-ability fit distinguished to other fits (i.e., PO, PS, PG, PJ fit) that evidenced PE fit would be mediated the relationship between emotional labor and job involvement. Obviously, partially indirect effect is the strongest mediated the relationship between emotional labor and job involvement. According to the empirical investigation of Hsu (2019) that fit perceptions are better predictors of employees' attitudes and behaviors than objective fit. We suggest that the first frontline employee could maintain harmony psyches with suitable fits to resolve the problems of emotional labor. Moreover, when the human resource manager is recruiting new employee, they can conduct the fit concepts of "KSACs (knowledge, sills, abilities, and other competencies)" in selection program.

This paper does not examine the moderation and moderated-mediation effects between emotional labor and job involvement, future research may research this issue. This study of participants surveyed in only employees-related perceived emotional display, so an illuminating extension of employers-related perceived emotional display would be to contribute the emotional labor literature in the future.

\section{References}

Avey, J. B., Luthans, F., \& Youssef, C. M. (2010). The additive value of positive psychological capital in predicting work attitudes and behaviors. Journal of Management, 36(2), 430-452.

Belsley, D. A., Kuh, E., \& Welsch, R. E. (1980). Regression diagnostics: Identifying influential data and sources of collinearity. New York: John Wiley.

Brown, S. P. (1996). A meta-analysis and review of organizational research on job involvement. Psychology Bulletin, 120(2), 235-255.

Cable, D. M., \& DeRue, D. S. (2002). The convergent and discriminant validity of subjective fit perceptions. Journal of Applied Psychology, 87(5), 875-884.

Cable, D. M., \& Judge, T. A. (1996). Person-organization fit, job choice decisions, and organization entry. Organizational Behavior \& Human Decision Processes, 67(3), 294-311.

Chuang, A., Shen, C. T., \& Judge, T. A. (2015). Development of a multidimensional instrument of personenvironment fit: The perceived person-environment fit scale (PPEFS)[Electronic version]. Applied Psychology: An International Review.

Comrey, A. L. (1988). Factor analytic methods of scale development in personality and clinical psychology. Journal of Consulting and Clinical Psychology, 56, 754-761.

Darvishmotevali, M., \& Ali, F. (2020). Job insecurity, subjective well-being and job performance: The moderating role of psychological capital. International Journal of Hospitality Management, 87, 102462.

Diefendorff, J. M., Croyle, M., \& Gosserand, R. (2005). The dimensionality and antecedents of emotional labor strategies. Journal of Vocational Behavior, 66(2), 339.

Diefendorff, J. M., Greguras, G. J., \& Fleenor, J. (2014). Perceived emotional demands-abilities fit. Applied Psychology, 63(3), 1-36.

Fox, C., Webster, B. D., \& Casper, W. (2018). Spirituality, psychological capital and employee performance: An empirical examination. Journal of Managerial Issues, 30(2), 194-213.

Gabriel, A. S., Daniels, M. A., Diefendorff, J. M., \& Greguras, G. J. (2015). Emotional labor actors: A latent profile analysis of emotional labor strategies. Journal of Applied Psychology, 100(3), 863-879.

Grandey, A. A. (2000). Emotion regulation in the workplace: a new way to conceptualize emotional labor. Journal of Occupational Health Psychology, 5(1), 95-110. 
Grandey, A. A., Diefendorff, J. M., \& Rupp, D. E. (2013). Bring emotional labor into focus: A review and integration of three research lenses. In A. A. Grandey, J. M. Diefendorff, \& D. E. Rupp (Eds.), Emotional Labor in the 21st Century: Diverse Perspectives on Emotion Regulation at Work (pp. 3-27). New York: Psychology Press/Routledge.

Hayes, A. F. (2012). PROCESS: A versatile computational tool for observed variable mediation, moderation, and conditional process modeling. [White paper]. Retrieved from http://www.afhayes.com/public/process2012.pdf

Hayes, A. F., \& Matthes, J. (2009). Computational procedures for probing interactions in OLS and logistic regression: SPSS and SAS implementations. Behavior Research Methods, 41, 924-936.

Hsu, P-F. (2015). The influence of emotional labor on job involvement: Under the different generation's moderating effects of perceived person-environment fit. Unpublished doctoral dissertation, University of Yunlin Science and Technology, Taiwan.

Hsu, P-F. (2019). Effect of reciprocal, perceived PE fit \& EL on JI. Singapore: Scholars' Press.

Hu, L., \& Bentler, P. M. (1999). Cutoff criteria for fit indexes in covariance structure analysis: Conventional criteria versus new alternatives. Structural Equation Modeling: A Multidisciplinary Journal, 6(1), 1-55.

Kanungo, R. N. (1982). Measurement of job and work involvement. Journal of Applied Psychology, 67(3), $341-49$.

Kristof-Brown, A. L., \& Billsberry, J. (2013). Fit for the future. In A. L. Kristof-Brown, \& J. Billsberry (Eds.), Organizational fit: Key Issues and New Directions (pp. 1-18). New York: John Wiley \& Sons.

Kristof-Brown, A. L., Zimmerman, R. D., \& Johnson, E. C. (2005). Consequences of individuals' fit at work: A meta-analysis of person-job, person-organization, person-group, and person-supervisor fit. Personnel Psychology, 58(2), 281-342.

Lauver, K. J., \& Kristof-Brown, A.L. (2001). Distinguishing between Employees' Perceptions of Person-Job and Person-Organization Fit. Journal of Vocational Behavior, 59(3), 454-470.

Lin, S. K., \& Hsu, P. F. (2021). The Influence of Emotional Labor on Job Involvement in Taiwan's Convenience Store: Compare the Effects of Moderating Role Among PJ Fit, PO Fit, PS Fit, and PG Fit. Asian Journal of Social Science Studies, 6(1), 17-26.

Lin, S. P. (2000). The development organization emotional labor scale, Sun Yat-Sen Management Review, 3(8), 427-447.

Preacher, K., \& Hayes, A. F. (2008). Asymptotic and resampling strategies for assessing and comparing indirect effects in multiple mediator models. Behavior Research Methods, 40(3), 879-891.

Tinsley, H. E., \& Tinsley D. J. (1987). Uses of factor analysis in counseling psychology. Journal of Counseling Psychology, 34, 414-424.

Wu, T. Y., \& Cheng, B. S. (2006). The Effect of Interactions among Job Involvement, Ability of Regulating Other's Emotion, and Emotional Labor on Emotional Exhaustion. Chinese Journal of Psychology, 48(1), 69-87.

Yoo, J. J., \& Arnold, T. J. (2014). Customer orientation, enagement, and developing positive emotional labor. The Service Industries Journal, 34(16), 1-18.

Zhang, L., Yu, S., \& Jiang, L. (2020). Chinese preschool teachers' emotional labor and regulation strategies. Teaching and Teacher Education, 92, 103024.

\section{Copyrights}

Copyright for this article is retained by the author(s), with first publication rights granted to the journal.

This is an open-access article distributed under the terms and conditions of the Creative Commons Attribution license (http://creativecommons.org/licenses/by/4.0/). 